Article

\title{
An Unobstructive Sensing Method for Indoor Air Quality Optimization and Metabolic Assessment within Vehicles
}

\author{
Yue Deng ${ }^{1,2, \dagger}{ }^{\text {, Mark Sprowls }}{ }^{1,2,+}$, S. Jimena Mora ${ }^{1} \mathbb{D}$, Doina Kulick ${ }^{3}$, Nongjian Tao ${ }^{4}$, \\ Hugo Destaillats ${ }^{5}$ and Erica Forzani ${ }^{1,2, *}$ \\ 1 School of Engineering for Matter, Transport, and Energy, Arizona State University, Tempe, AZ 85281, USA; \\ catherinedeng1015@gmail.com (Y.D.); mark.sprowls@asu.edu (M.S.); smora2@asu.edu (S.J.M.) \\ 2 Center for Bioelectronics and Biosensors, Biodesign Institute, Arizona State University, \\ Tempe, AZ 85281, USA \\ 3 Mayo Clinic, Scottsdale, AZ 85054, USA; Kulick.Doina@mayo.edu \\ 4 School of Electrical, Energy and Computer Engineering, Arizona State University, Tempe, AZ 85281, USA; \\ njtao@asu.edu \\ 5 Lawrence Berkeley National Laboratory, Indoor Environment Group, Berkeley, CA 94720, USA; \\ hdestaillats@lbl.gov \\ * Correspondence: eforzani@asu.edu \\ + Indicates equal contribution and co-first authorship.
}

Received: 27 September 2020; Accepted: 10 December 2020; Published: 16 December 2020

\begin{abstract}
This work investigates the use of an intelligent and unobstructive sensing technique for maintaining vehicle cabin's indoor air quality while simultaneously assessing the driver metabolic rate. $\mathrm{CO}_{2}$ accumulation patterns are of great interest because $\mathrm{CO}_{2}$ can have negative cognitive effects at higher concentrations and also since $\mathrm{CO}_{2}$ accumulation rate can potentially be used to determine a person's metabolic rate. The management of the vehicle's ventilation system was controlled by periodically alternating the air recirculation mode within the cabin, which was actuated based on the $\mathrm{CO}_{2}$ levels inside the vehicle's cabin. The $\mathrm{CO}_{2}$ accumulation periods were used to assess the driver's metabolic rate, using a model that considered the vehicle's air exchange rate. In the process of the method optimization, it was found that the vehicle's air exchange rate $\left(\lambda\left[\mathrm{h}^{-1}\right]\right)$ depends on the vehicle speeds, following the relationship: $\lambda=0.060 \times$ (speed) -0.88 when driving faster than $17 \mathrm{MPH}$. An accuracy level of $95 \%$ was found between the new method to assess the driver's metabolic rate $(1620 \pm 140 \mathrm{kcal} /$ day $)$ and the reference method of indirect calorimetry $(1550 \pm 150 \mathrm{kcal} /$ day $)$ for a total of $\mathrm{N}=16$ metabolic assessments at various vehicle speeds. The new sensing method represents a novel approach for unobstructive assessment of driver metabolic rate while maintaining indoor air quality within the vehicle cabin.
\end{abstract}

Keywords: indoor air quality; carbon dioxide accumulation; metabolic rate; energy expenditure; passive sensing

\section{Introduction}

Vehicle collisions have historically been one of the leading causes of preventable death in the United States. Increased legal focus on punishing distracted and/or inebriated drivers has had a surprisingly small effect on the annual number of vehicle-related casualties, as evidenced by the 7-year high in fatalities caused by vehicle collisions within the United States in 2016 [1]. Vehicle collisions and resulting injury are a serious burden to the U.S. healthcare system, with an estimated annual cost of $\$ 99$ Billion [2]. Recent developments in the field of air quality control have shown that $\mathrm{CO}_{2}$ buildup to 
$1000 \mathrm{ppm}$ and above frequently occurs in mid-size vehicles, especially with the use of recirculation mode [3-7]. $\mathrm{CO}_{2}$ is produced as a natural product of human metabolism and its accumulation within closed environments with insufficient ventilation can lead to accumulation. $\mathrm{CO}_{2}$ overexposure has been associated with reduced cognitive performance. These effects have been shown to be present at or above $1000 \mathrm{ppm} \mathrm{CO}$, and worsen significantly when $\mathrm{CO}_{2}$ concentration reached $2500 \mathrm{ppm}$ or higher in laboratory settings [8-11]. A recent study has evaluated the effect of similar $\mathrm{CO}_{2}$ levels on commercial airplane pilots performing maneuvers in a flight simulator showing a correlation of elevated $\mathrm{CO}_{2}$ concentrations with lower flight maneuver success, independent of ventilation [12]. As such, $\mathrm{CO}_{2}$ concentration monitoring within vehicles may be of great value to public health from a safety perspective.

On a separate area, the air exchange rate ( $\lambda$, referred to as AER or ACH in other works) from a vehicle's cabin have been extensively studied, as well as the effect of driving speed on air exchange rate [13-17]. A major factor leading to $\mathrm{CO}_{2}$ accumulation in vehicle cabins is the use of recirculation (RC) mode, since most of the $\mathrm{CO}_{2}$ exhaled by occupants is not vented outside when this ventilation setting is selected. For comfort and energy efficiency purposes, in many vehicles the RC mode is automatically turned on when the air conditioning is operating. The presence of additional occupants within a vehicle further accelerates $\mathrm{CO}_{2}$ buildup [18]. $\mathrm{CO}_{2}$ accumulation patterns have also been simulated using training data from a large set of vehicles in [4], which provides a guide for predicting maximum $\mathrm{CO}_{2}$ concentrations during drives of various lengths while using RC mode. However, other works rely on air exchange rate measurement in vehicles using tracer gas techniques, previously $\mathrm{SF}_{6}$ has been documented in vehicles for this purpose [14], or on steady-state measurements of $\mathrm{CO}_{2}$ concentration [13], which can be inconvenient. We report here a method of $\lambda$ evaluation from unsteady-state (transient) $\mathrm{CO}_{2}$ accumulation data that poses significant advantages over both methodologies mentioned above. The new method does not require the use of exogenous trace gas and allows accumulation of $\mathrm{CO}_{2}$ at the steady-state level, which can reach dangerous levels (e.g., $2548 \mathrm{ppm}$ for a single subject driving at $32 \mathrm{~km} / \mathrm{h}$ [13]).

The present work strives to investigate the use of an unobstructive sensing method relying on unsteady-state (transient) $\mathrm{CO}_{2}$ accumulation measurement for maintaining vehicle cabin's indoor air quality and assessing the driver's metabolic rate, using a previously derived model [19] and pre-calibrated car's air exchange rate as a function of driving speed. This system could potentially leverage the wealth of data collected and resulting general linear model in [13], which takes into account a wide fleet of vehicles of various ages and manufacturers to estimate $\lambda$ for a given vehicle based on manufacturer and age.

In the field of nutritional medicine, $\mathrm{CO}_{2}$ production has a close mathematical relationship with human metabolic rate, referred to as energy expenditure (EE), and expressed in kcal/day [20]. EE is the key physiological metric used to take a medical intervention for clinically obese patients since it allows medical doctors to make recommendations for calorie consumption on a given day based on their patient's rate of energy consumption [21]. This study probes the feasibility of EE determination by quantifying the volumetric production rate of $\mathrm{CO}_{2}\left(\mathrm{VCO}_{2}\right)$, expressed in $\mathrm{mL} / \mathrm{min}$ using only ambient and non-wearable sensors. Measuring $\mathrm{EE}$ based on ambient $\mathrm{CO}_{2}$ production using only one portable $\mathrm{CO}_{2}$ sensor within a vehicle is a promising approach. Methods for ambient $\mathrm{VCO}_{2}$ measurement do exist, but depend on $\mathrm{CO}_{2}$ measurements in inlet and outlet ducts in a room with controlled mechanical ventilation, making the system's installation too cumbersome for widespread usage [22]. Other medical devices require the use of breathing hardware that prevents free living EE determinations, are time consuming and discourage repeated measurements [23]. This study describes initial step towards validation of a medical device for EE quantification in a controlled indoor microenvironment. Overall, the development of this device fits into a larger growing trend in the field of cutting edge biomedical diagnostics which in coming years may be largely characterized by what can be described best as "minimally invasive IoT (internet of things) medical devices and biosensors" [24-27]. The basic premise of this growing field of biomedical diagnostics is to engineer minimally invasive medical devices that 
allow for clinically relevant biometrics to be collected repeatedly on the order of days, weeks, or months in a manner that is minimally obtrusive (i.e., no blood sampling, minimal user time commitment for collection, ambient sensing, use of wearables) and provides relevant health biometrics to clinicians without sacrificing accuracy (or partially mitigating lower accuracy with massive sample size that invasive devices fail to feasibly achieve for the everyday patient). However, IoT sensors are not only promising for the field of medical devices, but also for the purpose of environmental data collection and also, in some cases, (such as the method this work proposes) artificially intelligent closed-loop actuation control. Following this line of reasoning, the ideal intelligent vehicle air quality optimization system could be potentially multiplexed with a sensing approach that also considers outdoor toxic pollutants such as $\mathrm{NO}_{2}$, and, therefore, an array of $\mathrm{NO}_{2}$ and $\mathrm{CO}_{2}$ using IoT sensors could be placed together to make intelligent decisions in the utilization of RC mode or regular air conditioning (AC) mode depending on air quality conditions and current concentrations of both chemical species to minimize driver risk. With recent developments in triboelectricity-based $\mathrm{NO}_{2}$ sensors $[28,29]$, this is a very real possibility and may be the focus of future works.

A comprehensive assessment of $\mathrm{CO}_{2}$ levels inside a car cabin was conducted, including experimental characterization and model simulation. Our team studied the $\mathrm{CO}_{2}$ production rate by a single occupant (driver) and the cabin air exchange rate $(\lambda)$ under one fan condition and driving speeds. These results allowed for the assessment of the driver's energy expenditure. A box model was used to predict the $\mathrm{CO}_{2}$ concentration profile within a vehicle under various conditions.

\section{Materials and Methods}

\subsection{Experimental Characterization}

\subsubsection{Experimental Setup}

A set of tests was carried out by a single investigator driving a vehicle on residential streets and highway within the greater Phoenix area, Arizona, USA, between August 2017 and July 2018. The vehicle tested was a 2012 Hyundai Elantra. Its age at the time of the tests (5-6 years) and interior volume (110 $\mathrm{ft}^{3}$, or $\left.3.1 \mathrm{~m}^{3}\right)$ ("2012 Hyundai Elantra Features \& Specs,") are very close to the median values for the current US gasoline-fueled light duty vehicle fleet (8 years and $110 \mathrm{ft}^{3}$, respectively) [4]. The study was approved by Arizona State University Institutional Review Board (IRB protocol \# STUDY00006547). The subject (car driver) was a healthy 27-year-old female. The test subject provided written informed consent before participating in the study.

\subsubsection{Sensing System}

The custom-made measurement system consisted of a Telaire ${ }^{\circledR} 7001 \mathrm{CO}_{2}$ sensor (Onset Corp, Bourne, MA, USA) and a $\mathrm{HOBO}^{\circledR}$ temperature and humidity sensor (Onset Corp, Bourne, MA, USA), as described in our previous publication [19]. The system was calibrated with $\mathrm{CO}_{2}$ gas samples of different concentrations in the range of 0-3000 ppm. In addition, prior to each experiment, a quality control procedure was applied for every measurement assuring the reading of outer $\mathrm{CO}_{2}$ concentration roughly matched the expected value ( $\sim 400 \mathrm{ppm})$, to ensure the outdoor environment was free of any urban or biogenic source.

\subsubsection{Measurements and Sensing Methods}

During the test, the sensing system was placed on top of the front passenger seat, approximately one meter from the driver. Real-time $\mathrm{CO}_{2}$ concentration, temperature, and humidity were recorded with a resolution of $1 \mathrm{~s}^{-1}$. All tests were conducted at times of low traffic for consistent driving speed and to avoid introducing $\mathrm{CO}_{2}$ by air exchange with the outside environment, since $\mathrm{CO}_{2}$ effluent from surrounding vehicle exhaust could enter the vehicle cabin as car exhaust is a form of highly concentrated $\mathrm{CO}_{2}$ (relative to regular atmospheric levels). Additionally, it is reasonable to postulate 
exhaust streams are at a higher pressure than the internal car cabin pressure (due to engine heat, among other factors) and are high in $\mathrm{CO}_{2}$ concentration since they are fuel effluent which would serve as a source of error for observed $\mathrm{CO}_{2}$ accumulation patterns if it were not controlled by driving at low traffic times.

A picture of the vehicle model used in the study is shown in Figure 1a. Figure $1 \mathrm{~b}$ shows the AC dashboard, including fan speed level and an independent control to select between RC or air exchange mode.

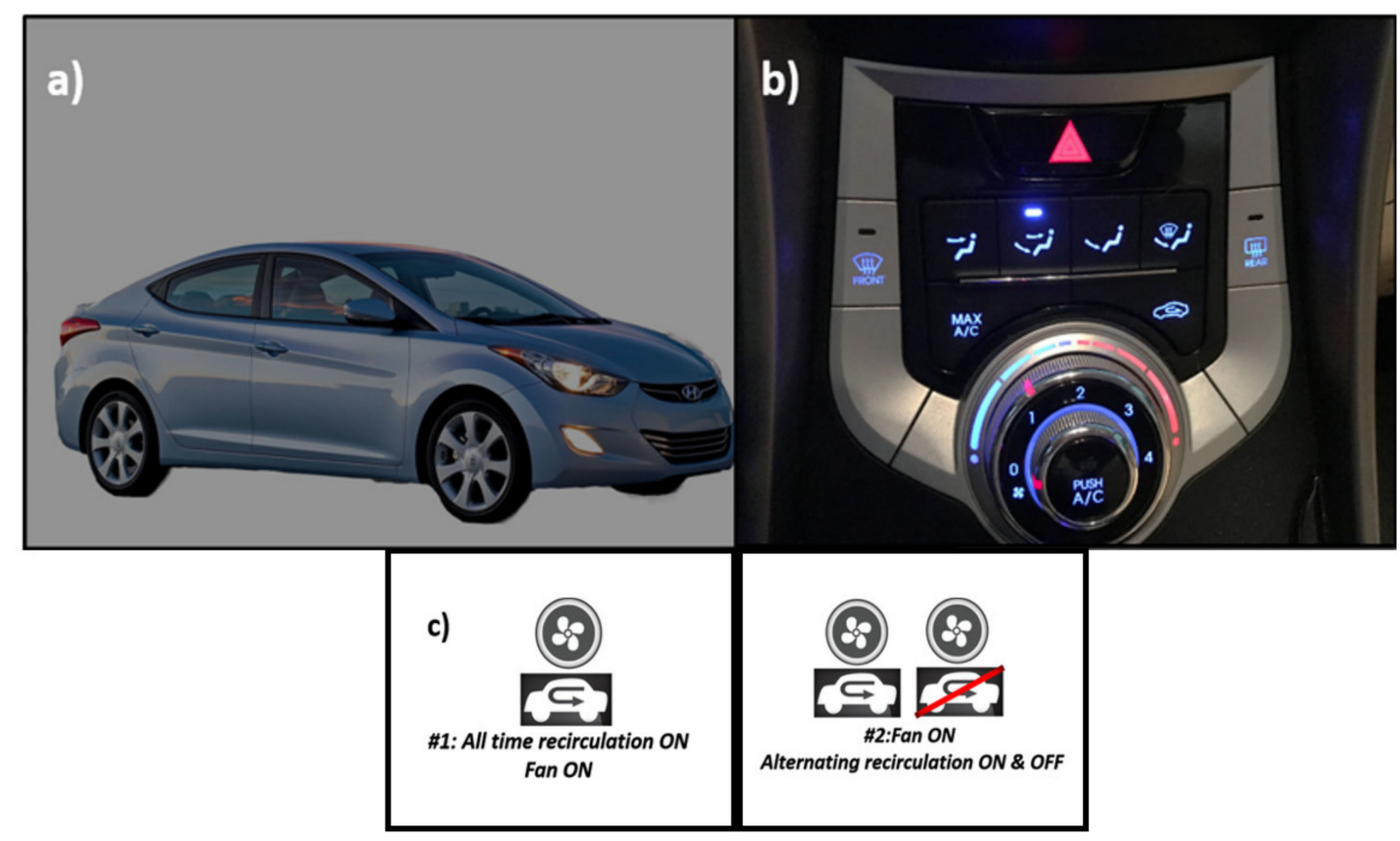

Figure 1. (a) Vehicle used in this study; (b) AC control panel; (c) Two different testing conditions, see text for detail.

Two different ventilation methods were used with the car windows closed, as described in Figure 1c:

Method \#1-Continuous RC (recirculation) mode: In this method, the RC mode was on and the fan was kept at level 1 during the tests. Five different driving speeds were tested under this condition: $0 \mathrm{MPH}$ (miles per hour), 15-17 MPH, 33-35 MPH, 48-50 MPH and 68-70 MPH. To achieve different level of speed, the tests were conducted on residential roads (Broadway and Rural road in Tempe, AZ, USA) and highway (AZ Loop 101, Loop 202 and Interstate 10 in Arizona) accordingly. The speed log of each test was recorded with the RunKeeper ${ }^{\circledR}$ app (ASICS Digital, Boston, MA, USA). The test was stopped once the cabin $\mathrm{CO}_{2}$ concentration reached $2000 \mathrm{ppm}$ or if the test had lasted $0.8 \mathrm{~h}$. These tests were performed 3 times at each speed. One growth curve is provided at each speed as an example.

Method \#2-Continuous ventilation and intermittent RC mode: In this method, the RC Mode is intermittently $\mathrm{ON}$ and $\mathrm{OFF}$ with the continuous ventilation $\mathrm{ON}$ at a fan level 1. The RC was turned OFF and actuated based on the $\mathrm{CO}_{2}$ levels inside the vehicle's cabin. These levels were between baseline level of $\sim 450$ ppm for fresh air and threshold levels of 1000-1100 ppm for air resulting from the $\mathrm{CO}_{2}$ accumulation due to the driver's breathing. In other words, the RC mode was initially on and was turned off for five minutes once the cabin $\mathrm{CO}_{2}$ concentration reached around 1000-1100 ppm, to allow for air exchange with the external environment and reduction of $\mathrm{CO}_{2}$ levels within the vehicle cabin. Under this condition, four different driving speeds were tested: $0 \mathrm{MPH}, 15-17 \mathrm{MPH}, 33-35 \mathrm{MPH}$ and 65-68 MPH. The roads taken for this set of tests were the same as condition \#1. Each test was performed within a single $1 \mathrm{~h}$ span. The RC mode was switched ON/OFF 4 times total within the hour 
for each speed tested. This rendered 4 separate growth curves (and, therefore, 4 separate metabolic rate measurements).

\subsubsection{Local Concentration Gradients within Vehicle}

A previous computational fluid dynamics (CFD) study [30] has shown that, in theory, $\mathrm{CO}_{2}$ concentration gradients [ppm] within the occupied vehicle do not vary by greater than an order of magnitude, in most cases and except at geometric boundary conditions. In our experimental conditions, the effects of mixing and the presence of concentration gradients were examined with the vehicle at rest, showing little variability.

\subsection{Simulation and Data Analysis}

\subsubsection{Carbon Dioxide Accumulation Analysis}

Ji et al. [31] has previously considered a model for human-generated $\mathrm{CO}_{2}$ accumulation. However, the model applies only to conditions of a human inside a perfectly sealed small chamber, with no leakage between the chamber and its surroundings. Using a model described in our previous study and which accounts for air leakage in the environment, which are representative of realistic human free-living conditions [19], a computational simulation was used to predict $\mathrm{CO}_{2}$ accumulation patterns for various scenarios based on the solution of a total differential equation for changes in $\mathrm{CO}_{2}$ concentration with respect to time. The developed model was simulated using MATLAB ${ }^{\circledR}$ (MathWorks Inc., Natick, MA, USA) and assumes that $\frac{d\left[\mathrm{CO}_{2}\right]}{d t}$ is first order with respect to $\mathrm{CO}_{2}$ concentration and 0th order with respect to $\mathrm{CO}_{2}$ generation (i.e., the amount of $\mathrm{CO}_{2}$ generated by occupants does not depend on $\mathrm{CO}_{2}$ concentration). The solved differential equation for $\mathrm{CO}_{2}$ generation is as follows:

$$
\left[\mathrm{CO}_{2}\right]=\left[\mathrm{CO}_{2}\right]_{0}+\frac{K_{\text {gen }}}{\lambda}\left(1-e^{-\lambda t}\right)+\left[\mathrm{CO}_{2}\right]_{i} e^{-\lambda t}
$$

where $\left[\mathrm{CO}_{2}\right]_{0}$ is the ambient $\mathrm{CO}_{2}$ concentration $(\sim 400 \mathrm{ppm}),\left[\mathrm{CO}_{2}\right]_{i}$ is the difference between the initial $\mathrm{CO}_{2}$ concentration at the beginning of the fitted curve and the baseline $\mathrm{CO}_{2}$ concentration, $k_{\text {gen }}$ is $\mathrm{CO}_{2}$ generation rate with units of ppm $\mathrm{CO}_{2} \mathrm{~h}^{-1}$, and $\lambda$ is the air exchange rate in $\mathrm{h}^{-1}$. The volumetric production rate of $\mathrm{CO}_{2}\left(\mathrm{VCO}_{2}[\mathrm{~mL} / \mathrm{min}]\right.$ by the vehicle's occupant can be calculated as follows and is simply derived from the ideal gas law and a mass balance on $\mathrm{CO}_{2}$ within the cabin:

$$
V C \mathrm{O}_{2}=k_{\text {gen }} \times V_{\text {Room }} \times C F_{S T P D} / 60
$$

where $\mathrm{VCO}_{2}$ is the subject's volumetric production of $\mathrm{CO}_{2}[\mathrm{~mL} / \mathrm{min}], \mathrm{V}_{\text {Room }}$ is the volume of the vehicle cabin $[\mathrm{mL}]$ (taken from manufacturer-listed vehicle specifications), and $\mathrm{CF}_{\mathrm{STPD}}$ [dimensionless] is a correction factor to correct the $\mathrm{VCO}_{2}$ at ambient temperature and pressure conditions (ATP) to standard temperature, pressure, and dry conditions (STPD). The correction factor was calculated as follows:

$$
C F_{S T P D}=\frac{P_{b a r}-P_{H 20}}{760} \times \frac{273}{T+273}
$$

\subsubsection{Effect of Car Occupant's Metabolic Rate}

The proportion of a person's $\mathrm{CO}_{2}$ production rate $\left(\mathrm{VCO}_{2}\right)$ to $\mathrm{O}_{2}$ consumption rate $\left(\mathrm{VO}_{2}\right)$ is known as the respiratory quotient $(\mathrm{RQ})$ and its value depends on the ratios of metabolized energy sources within a person's body (e.g., RQ for carbohydrate metabolism $=1.0$; fat metabolism $=0.71$; protein metabolism $=0.82)$ [32]:

$$
R Q(\text { Respiratory Quotient })=\frac{V C \mathrm{O}_{2}}{\mathrm{VO}_{2}}
$$


The relationship between $\mathrm{RQ}, \mathrm{VCO}_{2}$, and energy expenditure (EE) has been studied extensively and is the basis of the field of indirect calorimetry. The fundamental equation that links these 3 parameters is known as Weir Equation and it is shown below [33]:

$$
E E\left(\frac{k c a l}{d a y}\right)=1.44 \times\left[3.941 \times \frac{V C O_{2}}{R Q}+1.11 \times V C_{2}\right]
$$

For individuals following diets with relatively equal amounts of carbohydrates, protein, and fats, an RQ equal to or near 0.85 should be expected [34-36]. In this case, Equation (5) can be simplified to the following:

$$
E E\left(\frac{k c a l}{d a y}\right)=8.273 \times V \mathrm{CO}_{2}
$$

\subsubsection{Simulation Parameters}

It is important to mention that $\mathrm{EE}$ assessment is solely possible when we have a single occupant in the vehicle. For multiple occupants, $\mathrm{VCO}_{2}$ production will be representative of the driver + occupants. The multiple occupants could be detected with pressure sensors in the seat, and a combination of pressure sensors could discriminate if the occupant is a subject or an object. Under these conditions, an averaged EE value per occupant could be assessed. However, the indoor air quality aspect of the presented approach would be more relevant to assure the safety of the indoor air inside the cabin. Therefore, for the purpose of informing public policy that governs domestic roadways, it has great utility in the sense that this information can be used to build simulations detailing the $\mathrm{CO}_{2}$ concentration in various accumulation conditions (as done in Section 2.2.3 below) that are useful in assessing driving safety relative to $\mathrm{CO}_{2}$ concentration within the vehicle cabin.

The simulation presented in this work has been developed to extend the experimental findings introduced in this work's assessment to several other conditions that could not be tested. The model estimated the car cabin volume to be $3.1 \mathrm{~m}^{3}$, a baseline $\mathrm{CO}_{2}$ concentration of $400 \mathrm{ppm}$, a $\lambda$ of $1 \mathrm{~h}^{-1}$ (unless indicated otherwise), a linear relationship between $\lambda$ and car speed (validated by experimental findings presented in this work), a linear relationship between $\mathrm{CO}_{2}$ generation and the number of occupants within the vehicles, and an occupant energy expenditure $E E=1700 \mathrm{kcal} /$ day (unless indicated otherwise).

\section{Results}

\subsection{Experiments under Method \#1—Continuous RC (Recirculation) Mode}

The purpose of this set of experiments was to examine the intrinsic air exchange condition according to our group's derived model and explore its relationship with driving speed. Figure 2 summarized the results together with the average recorded speed, while real-time speed data are shown in Figure S2 (Supplementary Materials). Three experiments were performed at each speed on different days as replicate measurements.

We hypothesize that the increased leakage at higher driving speeds is due to the pressure difference between inside the cabin and the outside environment, generated by the vehicle movement, and Bernoulli principle of differential negative pressure causing a net flux of air out to the vehicle and into the surrounding environment due to the vehicle's velocity. Thus, it is reasonable to assume that at $0 \mathrm{MPH}$ (parked condition), there is significantly reduced leakage due to a negligible pressure difference. As summarized in our previous publication [19], under this condition, the $\mathrm{CO}_{2}$ concentration profile should follow a linear relationship. Applying linear fitting to $0 \mathrm{MPH}$ data, we determined the actual $\mathrm{CO}_{2}$ generation rate to be $K_{\text {gen }}=5344 \pm 66 \mathrm{ppm} / \mathrm{h}$. Additionally, to show that the vehicle's $\mathrm{CO}_{2}$ concentration is independent of engine operation (which of course, can be a source of $\mathrm{CO}_{2}$ ), an experiment was performed to assess the cabin's $\mathrm{CO}_{2}$ concentration with the vehicle's engine on, the vehicle stationary, unoccupied, and with recirculation mode on. Under these conditions, it could 
be clearly observed that there is no $\mathrm{CO}_{2}$ accumulated within the vehicle's cabin from engine exhaust. This error mitigation assessment is shown in Figure S1 of the Supplementary Materials.
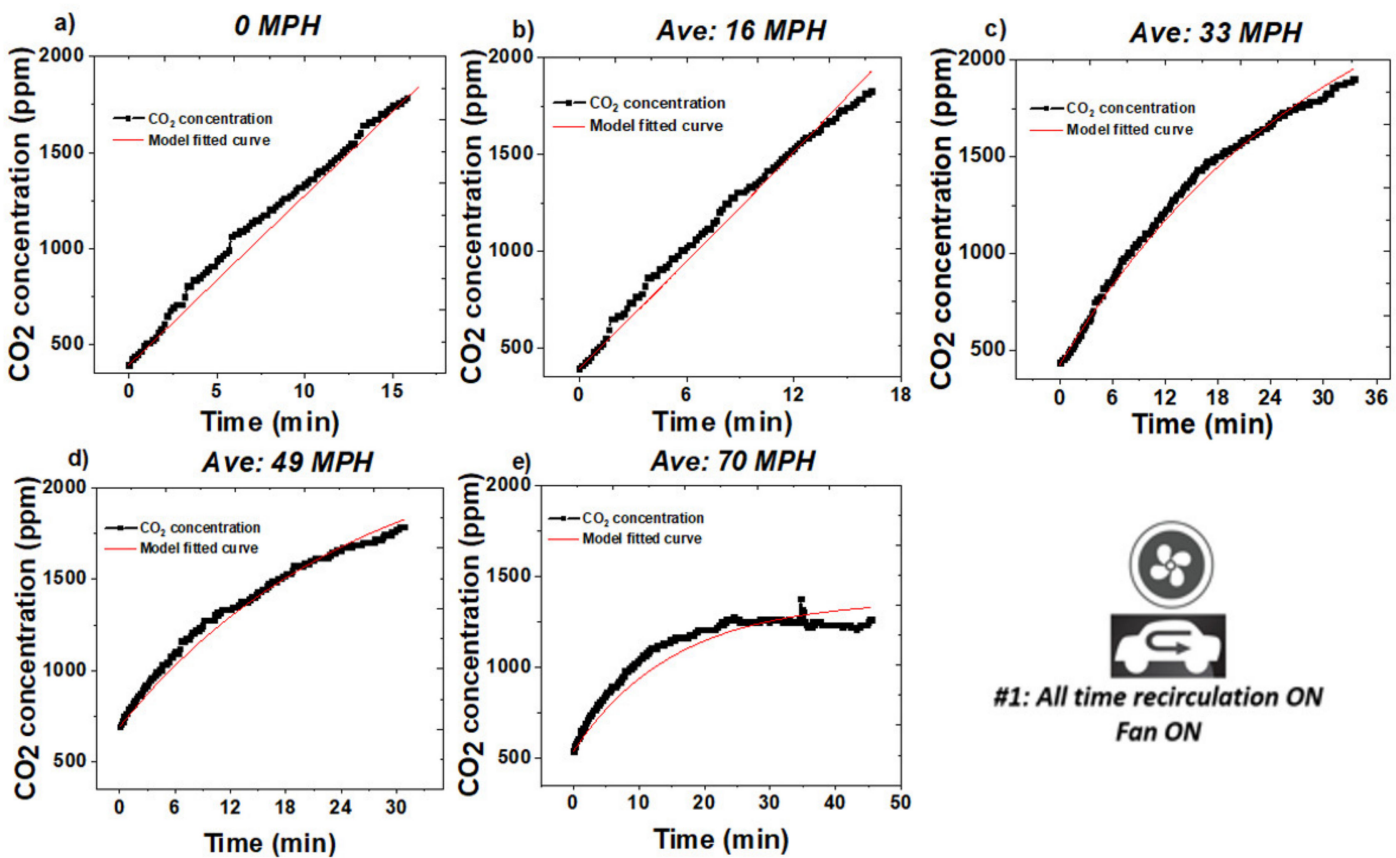

Figure 2. $\mathrm{CO}_{2}$ concentration inside the vehicle cabin under different driving speed, all-time recirculation (RC) on mode. (a) $0 \mathrm{MPH}$ (parked); (b) $16 \mathrm{MPH}$; (c) $33 \mathrm{MPH}$; (d) $49 \mathrm{MPH}$; (e) $70 \mathrm{MPH}$.

In each of the replicate experiments, five tests at different speeds were carried out consecutively in a $3 \mathrm{~h}$ period, during which the driver remained seated at the wheel. For that reason, the driver's energy expenditure was considered to be relatively constant over the course of the experiment. Using the experimentally determined $K_{g e n}$ value and Equation (1), we determined the effective air exchange $\lambda$ for each speed.

The model fitted $\lambda$ results are shown in Figure 3. The error bars for each speed is the standard deviation from three replicates. It is observed that in the range of $0-18 \mathrm{MPH}, \lambda$ is close to 0 . Thus, we define that when the speed is less than $17 \mathrm{MPH}$, the intrinsic air exchange is negligible. By applying linear fitting for speeds $>17 \mathrm{MPH}$, we could calculate the relationship between $\lambda$ and driving speed, as presented in Figure 3. The regression coefficient $\left(\mathrm{R}^{2}\right)$ equals 0.99 , indicating a strong correlation between the two parameters. As can be observed in the Supplementary Materials for this work (Figure S2), vehicle speed did not remain constant during each nominal driving speed. In fact, there was a moderate degree of variance. However, the average of the driving speed allowed the output variables of $\lambda$ or EE to be assessed, depending on the driving condition. Therefore, from the collected data, it is not unreasonable to hypothesize that "the collected data suggests that even when there is a moderate degree of variation within vehicle velocity, the proposed model still remains.

This result is also consistent with other reports showing that higher driving speeds resulted in slower $\mathrm{CO}_{2}$ concentration growth profiles [4]. However, quantitatively, results differed from those predicted in the model described in [13], where the predicted $\lambda^{\prime}$ s were at least 2x greater than the results observed in the present study. Potential reasons for this discrepancy are the car manufacturer (Korean manufacturer adjustment not available for the model, as such, Japanese adjustment was used instead) and also that no vehicles from a 2012 fleet were tested in Fruin's 2011 work. Additionally, in Fruin's 2011 work, the technique for $\lambda$ (referred to as AER in Fruin's work) assessment relied on analysis of concentration equilibrium conditions, whereas, the present work relies on analysis of unsteady-state $\mathrm{CO}_{2}$ growth curves. In another work [14], characterizing $\lambda$ using the constant injection $\mathrm{SF}_{6}$ tracer gas technique, observed air exchange rates were within the normal range for the vehicle tested in the 
present study, indicating that the $\mathrm{CO}_{2}$ analysis technique used in the present work coincides well with previous literature values for $\lambda$ assessment using a different technique. One significant limitation of the present work is that wind speed and outdoor concentration were not tested as in [13], as these factors can have a significant effect, also shown in [14,15].

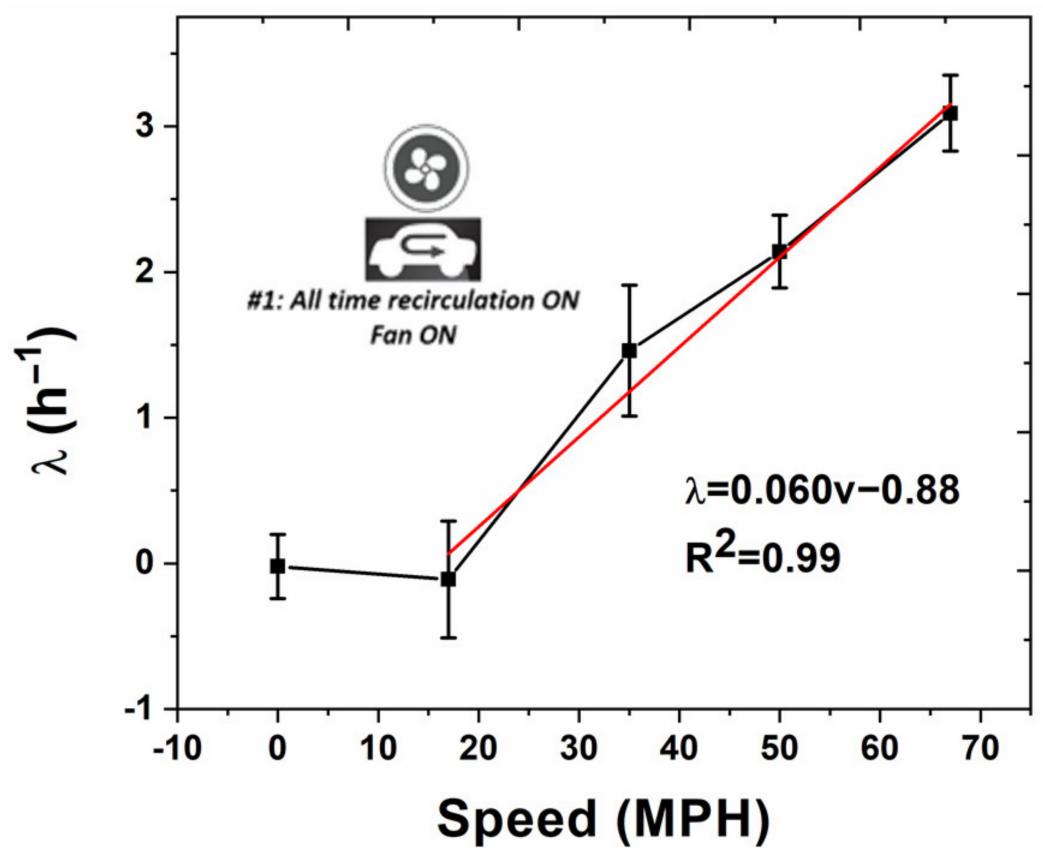

Figure 3. Relationship between the effective air exchange rate $(\lambda)$ and driving speed $(v)$. Red line indicates linear regression curve above $17 \mathrm{MPH}$.

\subsection{Experiments under Method \#2-Continuous Ventilation and Intermittent RC Mode}

Under this condition, the $\mathrm{CO}_{2}$ concentration was kept under 1100 ppm by alternating $\mathrm{RC}$ on and off, and the fan ventilation level at 1 . Typically, in one measuring cycle, RC mode would be left on for about $5 \mathrm{~min}$ and then turned off for 5 min once the $\mathrm{CO}_{2}$ concentration reached $1100 \mathrm{ppm}$. The aim was to assess energy expenditure during the growth periods of $\mathrm{CO}_{2}$ buildup, and validate the model (by comparing using EE measurements taken from a reference instrument) at a condition where recirculating cabin air (RC mode) and outside air ventilation were alternated. Since regular, non-RC mode ventilation consumes more of the vehicles fuel in operation in comparison with RC mode [37], this condition is a practical solution to assure good quality levels in the air inside the car cabins while minimizing the fuel efficiency losses due to car cabin ventilation. In addition, these experimental conditions allow for the assessment of energy expenditure with the added benefit of being able to perform multiple EE measurements within a single trip, which improves the system's accuracy with respect to assessment of the driver's average energy expenditure. This is the true highlight of the observed data, as it is already known that turning off $\mathrm{RC}$ mode will mitigate $\mathrm{CO}_{2}$ buildup within vehicles.

Real-time $\mathrm{CO}_{2}$ profiles are shown in Figure 4. The model was applied for a $\lambda$ of $0.05 \mathrm{~h}^{-1}$, which is a non-null but negligible value for speeds lower than $18 \mathrm{MPH}$. The assessment of this condition was based on the experimental observation that at parked and at low speeds, the air exchange rate between the vehicle cabin and the environment was negligible. For speeds greater than $18 \mathrm{MPH}$, the $\lambda$ was calculated from the regression equation shown in Figure 3 and used in Equation (1) to determine the real $K_{\text {gen }}$ for each $\mathrm{CO}_{2}$ growth period test cycle obtained during the periods of 36-48 min driving at a certain speed. Real-time speed data are shown in Figure S3 (Supplementary Materials). 

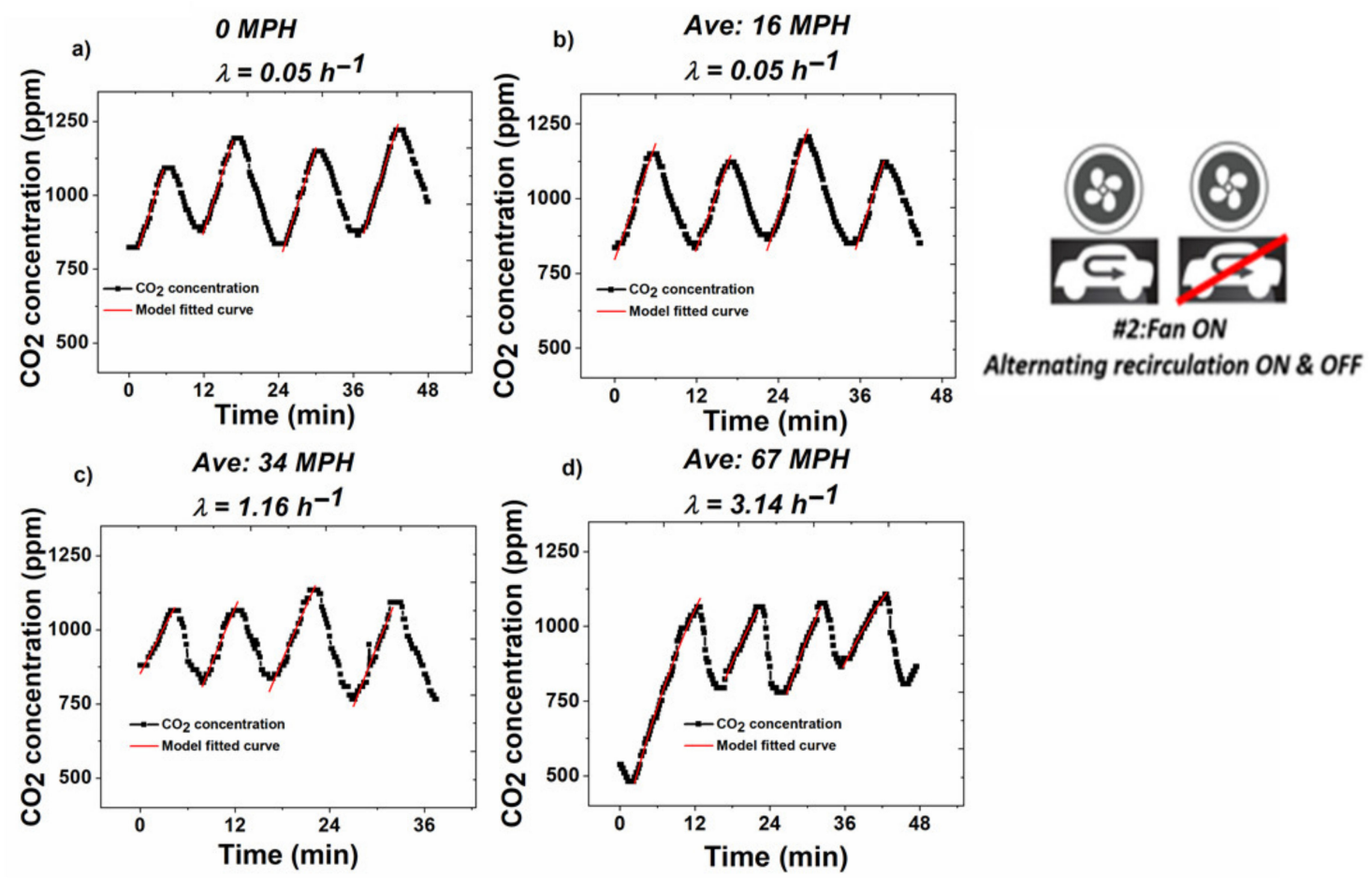

Figure 4. Real-time $\mathrm{CO}_{2}$ concentration profile and the model fitted curve (red) under different driving speed. (a) $0 \mathrm{MPH}$; (b) $16 \mathrm{MPH}$; (c) $37 \mathrm{MPH}$; (d) $64 \mathrm{MPH}$.

$\mathrm{VCO}_{2}$ values calculated using Equation (1) for fitting $\mathrm{CO}_{2}$ accumulation data and then decomposing the $\mathrm{K}_{\text {gen }}$ term to provide an estimate for $\mathrm{VCO}_{2}$ via equation 2, were then used to calculate $E E$ using Equation (4) for each growth cycle, using results from four cycles obtained at each speed, and averaged for that speed. For these four tests, the $E E$ value ranged from $1420 \mathrm{kcal} /$ day to $1730 \mathrm{kcal} /$ day with an average of $1620 \pm 140$ (kcal/day). The results are shown in Figure 5 for the averages with their corresponding standard error. The coefficient of variation from four tests remained at $8.6 \%$, indicating there was no significant $E E$ change during the test at each driving speed ( $36-48 \mathrm{~min}$ ). This is consistent with our hypothesis in Section 2.1 that the participant remained in a stable metabolic state over the duration of the driving tests. Another important finding was that energy expenditure fluctuated randomly within a relatively narrow range of values. The random variability $( \pm 15 \%)$ reflects the typical clinical variability expected for an energy expenditure measured at free-living conditions [38]. These results confirm that energy expenditure is independent from vehicle velocity.

Energy expenditure measured during driving tests were compared with those determined with conventional instrumentation. The subject's energy expenditure (or metabolic rate) while sitting in a computer and working was measured by indirect calorimetry using two different instruments: the desktop Korr Reevue ${ }^{\mathrm{TM}}$ (www.korr.com, Salt Lake City, UT, USA) and the Breezing Pro ${ }^{\mathrm{TM}}$ (https: //breezing.com/, Tempe, AZ, USA), obtaining an average of $(1550 \pm 150) \mathrm{kcal} /$ day for 10 measurements utilizing both indirect calorimetry instruments ( 5 readings each). This represents only $\sim 4 \%$ difference in comparison with our calculated $E E$ value. It should be noted that the participant did not perform any intense activity on the days of tests, since strenuous exercise increase a person's instantaneous energy expenditure [38]. The results demonstrated that this model could be used to determine EE of drivers, as the difference between mean values determined with each method was lower than the relative error for each of them. However, it is of course important to note that the subject did not perform the reference instrument $E E$ assessments simultaneously while driving, due to safety concerns regarding vehicle operation. 


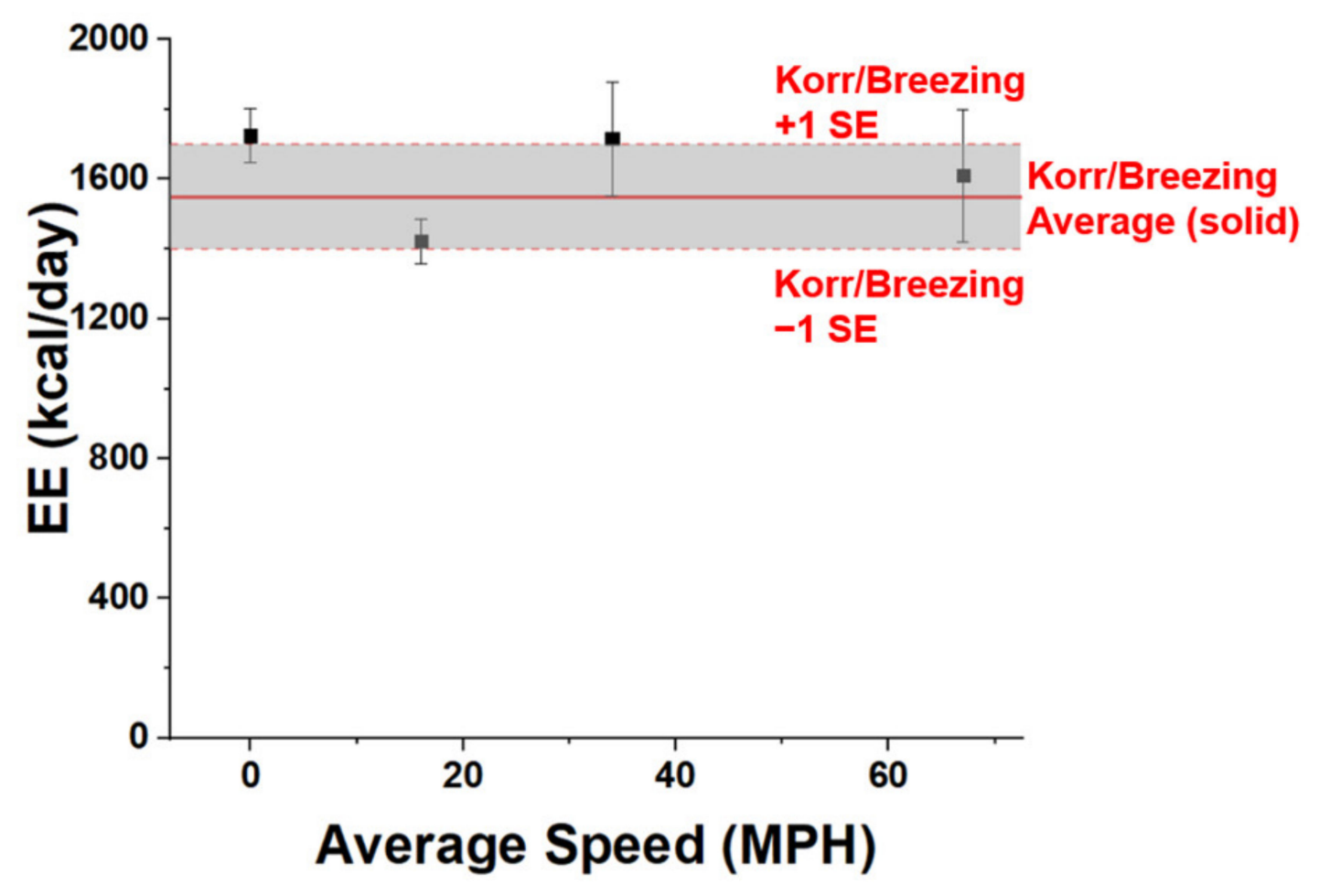

Figure 5. Energy Expenditure (EE) estimates generated from experimental data shown in Figure 4 (shown as black points with error bars) and corresponding reference instrument (Korr Reevue ${ }^{\mathrm{TM}}$ and Breezing Pro ${ }^{\mathrm{TM}}$ ) measurements shown as horizontal redline (average) \pm 1 standard error.

\section{3. $\mathrm{CO}_{2}$ Concentration Profile Modeling}

To expand upon the experimental results shown in the previous sections of this work, a computational simulation was developed using $M A T L A B^{\circledR}$ to generate model $\mathrm{CO}_{2}$ growth profiles under various conditions that were not investigated experimentally in this study. Figure 6 simulates $\mathrm{CO}_{2}$ concentration growth profiles inside a car cabin (RC mode on) with different number of occupants under various speeds. A horizontal line has been drawn at both 1000 and $2500 \mathrm{ppm}$ with a label to indicate the corresponding time at which a vehicle with a single occupant reaches the aforementioned $\mathrm{CO}_{2}$ concentration, used as a reference from recent cognitive performance studies [8-11]. The simulation predicts that $\mathrm{CO}_{2}$ levels within the car cabin reach $1000 \mathrm{ppm}$ for a single occupant in less than $15 \mathrm{~min}$ with $\mathrm{RC}$ mode on. $\mathrm{CO}_{2}$ accumulation is significantly higher for car cabins where there is more than one occupant; this is clearly evidenced in the simulation's output where $\mathrm{CO}_{2}$ levels exceeding $2500 \mathrm{ppm}$ are reached in under $15 \mathrm{~min}$ when the vehicle is occupied with at least three occupants, regardless of vehicle speed.

Figure 7a shows how a $\mathrm{CO}_{2}$ profile can be affected by changing the effective air exchange rate from 1 to a higher value, up to $22 \mathrm{~h}^{-1}$, e.g., by alternating the RC mode on and off, and/or opening windows. It is worth noticing that although the lower $\lambda$ values of $1-3 \mathrm{~h}^{-1}$ represent the values assessed in the experimental results of this work, which involved the car windows being closed, higher $\lambda$ could be obtained with car windows opened and were included since this work represents a generic model that can be applicable to multiple other driving conditions. 

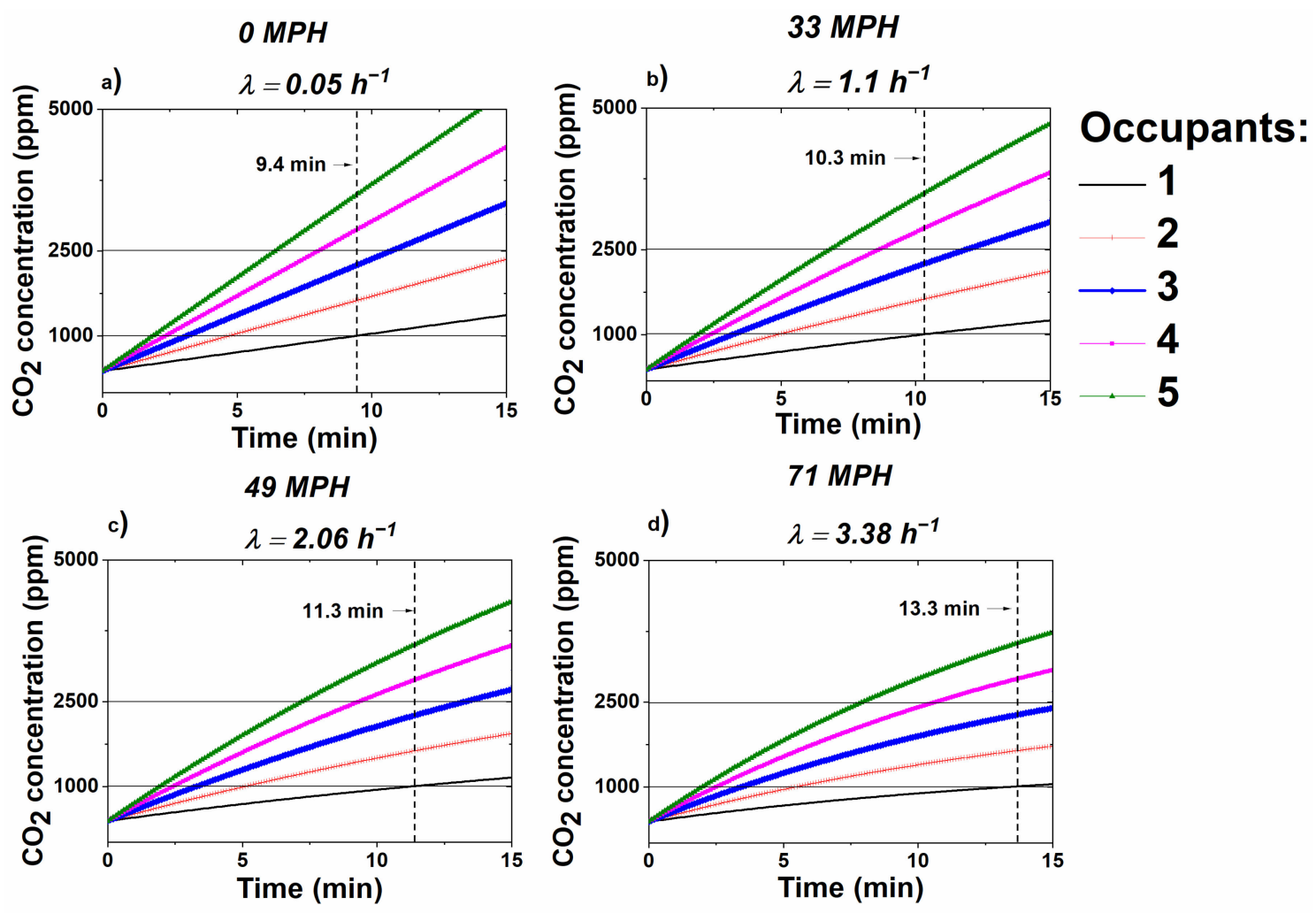

Figure 6. Modeled $\mathrm{CO}_{2}$ concentration profile for various driving speeds and number of occupants within vehicle. (a) $0 \mathrm{MPH}$; (b) $33 \mathrm{MPH}$; (c) $49 \mathrm{MPH}$; (d) $71 \mathrm{MPH}$.
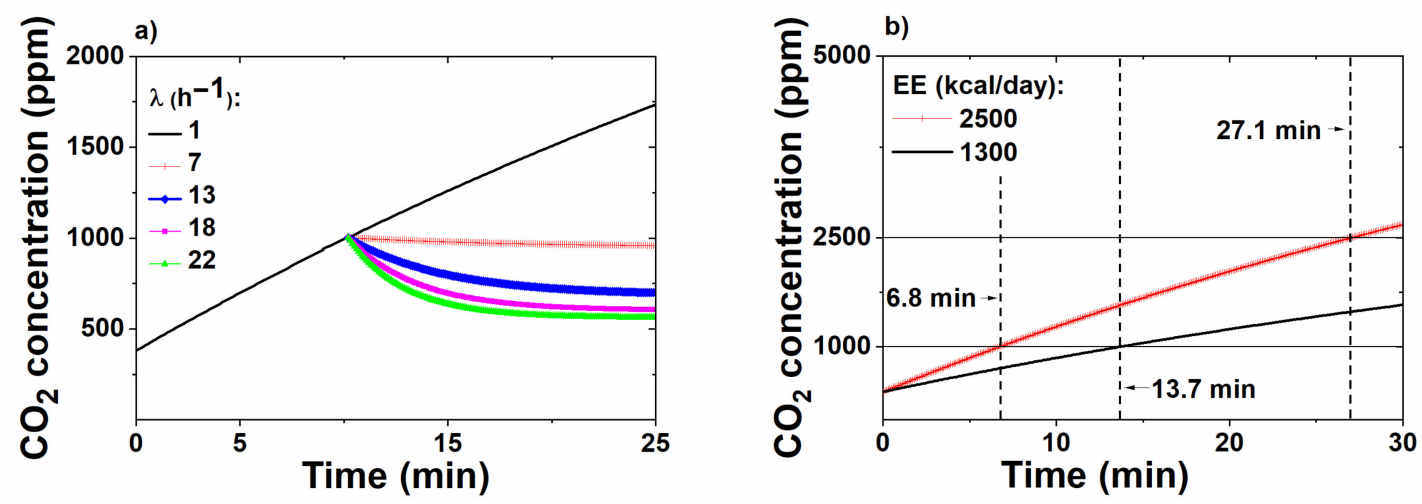

Figure 7. (a) Model $\mathrm{CO}_{2}$ concentration profile showing effect of air exchange rate on $\mathrm{CO}_{2}$ level; (b) Modeled $\mathrm{CO}_{2}$ concentration profile showing effect of metabolic rate on growth rate.

Figure $7 \mathrm{~b}$ demonstrates the effect of occupant metabolic rate on $\mathrm{CO}_{2}$ accumulation within a vehicle. This parameter has a substantial influence on the $\mathrm{CO}_{2}$ concentration growth profile. A driver with a relatively high $E E$ of $2500 \mathrm{kcal} /$ day will reach a $\mathrm{CO}_{2}$ concentration of $1000 \mathrm{ppm}$ in just $6.8 \mathrm{~min}$, as compared with virtually twice as long $(13.7 \mathrm{~min})$ for a driver spending only $1300 \mathrm{kcal} /$ day. The high- $E E$ driver can reach a $\mathrm{CO}_{2}$ concentration of $2500 \mathrm{ppm}$ in less than half an hour.

\section{Conclusions}

In the present work, we characterized transient $\mathrm{CO}_{2}$ buildup and the vehicle air exchange rates under different driving speeds. Most importantly, we developed a new method to assess the air exchange rate inside the car cabin under non-steady conditions by using the driver's energy expenditure rate as a known variable. This new method enabled the assessment of the air exchange rates and 
the car speed function, which further proved to be useful to assess the driver's energy expenditure repeated times under specific conditions of an on/off alternating ventilation. The results showed a good regression fitting $\left(\mathrm{R}^{2}>0.99\right)$ on a real-time $\mathrm{CO}_{2}$ concentration profile and accurate calculation for a single driver's $E E$ ( $4.4 \%$ difference with respect to determination using standard methods). Simulation results based on experimental data were also presented. The simulation serves to predict $\mathrm{CO}_{2}$ accumulation patterns due to various factors such as number of occupants and occupant energy expenditure. Overall, the investigations of this work allowed for the creation of an intelligent and unobstructive sensing method for maintaining vehicle cabin's indoor air quality and assessing the driver's metabolic rate.

Supplementary Materials: The following are available online at http://www.mdpi.com/1424-8220/20/24/7202/s1, Figure S1: Temperature, relative humidity $(\mathrm{RH})$, and $\mathrm{CO}_{2}$ concentrations versus time within a car while driving with the ventilation system closed, and the driver breathing in and out of the car cabin via a tubing system that preclude from exhale carbon dioxide buildup; Figure S2: $\mathrm{Raw} \mathrm{CO}_{2}$ monitor results together with real-time speed $\log$ for condition \#1; Figure S3: Raw $\mathrm{CO}_{2}$ monitor results together with real-time speed log for condition \#2.

Author Contributions: Y.D.: Performed Experiments and authored methodology, M.S.: Analyzed experimental data and authored the entire manuscript, S.J.M.: Aided in manuscript authorship, N.T., H.D., D.K.: Provided senior leadership and conceptual ideas for experimental planning and execution. N.T. and D.K. also helped to secure project funding. E.F.: Executive team member. Fully responsible for funding acquisition, correspondence, and project leadership. All authors have read and agreed to the published version of the manuscript.

Funding: This research received no external funding. All efforts were funded by the Ira A Fulton School of Engineering.

Acknowledgments: Special thanks to Lenore Dai, and Kyle Squires from Ira Fulton Schools of Engineering and the School for Engineering of Matter, Transport, and Energy at Arizona State University for providing the needed funds and equipment to conduct this study. Erica Forzani specially thanks NIH for R03EB027336, the Entrepreneur Professor Award to Ira A Fulton Schools of Engineering, Arizona State University and A.J. and Sigismunda Palumbo Charitable Trust. Hugo Destaillats' affiliation is provided for identification purposes only, as the work was not conducted with LBNL resources. This article is dedicated to Nongjian Tao, who passed away on 15 March 2020. He is missed by the team as a genius scientist, and excellent person.

Conflicts of Interest: Erica Forzani owns intellectual property related to this work.

\section{References}

1. NHTSA. National Highway Traffic Safety Administration. Quick Facts. 2016. Available online: https: //crashstats.nhtsa.dot.gov/Api/Public/Publication/812451 (accessed on 14 July 2020).

2. CDC. Center for Disease Control and Prevention. National Health Report Highlights. 2013. Available online: https://www.cdc.gov/healthreport/publications/compendium.pdf (accessed on 2 June 2020).

3. Barnes, N.M.; Ng, T.W.; Ma, K.K.; Lai, K.-M. In-Cabin Air Quality during Driving and Engine Idling in Air-Conditioned Private Vehicles in Hong Kong. Int. J. Environ. Res. Public Health 2018, 15, 611. [CrossRef] [PubMed]

4. Hudda, N.; Fruin, S. Carbon dioxide accumulation inside vehicles: The effect of ventilation and driving conditions. Sci. Total. Environ. 2018, 610-611, 1448-1456. [CrossRef] [PubMed]

5. Jung, H.; Grady, M.L.; Victoroff, T.; Miller, A.L. Simultaneously reducing $\mathrm{CO}_{2}$ and particulate exposures via fractional recirculation of vehicle cabin air. Atmos. Environ. 2017, 160, 77-88. [CrossRef] [PubMed]

6. Gładyszewska-Fiedoruk, K. Concentrations of carbon dioxide in a car. Transp. Res. Part D Transp. Environ. 2011, 16, 166-171. [CrossRef]

7. Gładyszewska-Fiedoruk, K. Concentrations of carbon dioxide in the cabin of a small passenger car. Transp. Res. Part D Transp. Environ. 2011, 16, 327-331. [CrossRef]

8. Allen, J.G.; Macnaughton, P.; Satish, U.; Santanam, S.; Vallarino, J.; Spengler, J.D. Associations of Cognitive Function Scores with Carbon Dioxide, Ventilation, and Volatile Organic Compound Exposures in Office Workers: A Controlled Exposure Study of Green and Conventional Office Environments. Environ. Health Perspect. 2016, 124, 805-812. [CrossRef]

9. Zhang, X.; Wargocki, P.; Lian, Z. Effects of Exposure to Carbon Dioxide and Human Bioeffluents on Cognitive Performance. Procedia Eng. 2015, 121, 138-142. [CrossRef] 
10. Satish, U.; Mendell, M.J.; Shekhar, K.; Hotchi, T.; Sullivan, D.; Streufert, S.; Fisk, W.J. Is $\mathrm{CO}_{2}$ an Indoor Pollutant? Direct Effects of Low-to-Moderate $\mathrm{CO}_{2}$ Concentrations on Human Decision-Making Performance. Environ. Health Perspect. 2012, 120, 1671-1677. [CrossRef]

11. Norbäck, D.; Nordström, K.; Zhao, Z. Carbon dioxide $\left(\mathrm{CO}_{2}\right)$ demand-controlled ventilation in university computer classrooms and possible effects on headache, fatigue and perceived indoor environment: an intervention study. Int. Arch. Occup. Environ. Health 2013, 86, 199-209. [CrossRef]

12. Allen, J.G.; Macnaughton, P.; Cedeno-Laurent, J.G.; Cao, X.; Flanigan, S.; Vallarino, J.; Rueda, F.; Donnelly-McLay, D.; Spengler, J.D. Airplane pilot flight performance on 21 maneuvers in a flight simulator under varying carbon dioxide concentrations. J. Expo. Sci. Environ. Epidemiol. 2018, 29, 457-468. [CrossRef]

13. Fruin, S.A.; Hudda, N.; Sioutas, C.; Delfino, R.J. Predictive Model for Vehicle Air Exchange Rates Based on a Large, Representative Sample. Environ. Sci. Technol. 2011, 45, 3569-3575. [CrossRef]

14. Knibbs, L.D.; De Dear, R.J.; Atkinson, S.E. Field study of air change and flow rate in six automobiles. Indoor Air 2009, 19, 303-313. [CrossRef]

15. Hudda, N.; Eckel, S.P.; Knibbs, L.D.; Sioutas, C.; Delfino, R.J.; Fruin, S. Linking in-vehicle ultrafine particle exposures to on-road concentrations. Atmos. Environ. 2012, 59, 578-586. [CrossRef]

16. Ott, W.R.; Klepeis, N.E.; Switzer, P.V. Air change rates of motor vehicles and in-vehicle pollutant concentrations from secondhand smoke. J. Expo. Sci. Environ. Epidemiol. 2007, 18, 312-325. [CrossRef]

17. Fletcher, B.; Saunders, C.J. Air change rates in stationary and moving motor vehicles. J. Hazard. Mater. 1994, 38, 243-256. [CrossRef]

18. Jiang, C.; Masood, M.K.; Soh, Y.C.; Li, H. Indoor occupancy estimation from carbon dioxide concentration. Energy Build. 2016, 131, 132-141. [CrossRef]

19. Ruiz, I.; Sprowls, M.; Deng, Y.; Kulick, D.; Destaillats, H.; Forzani, E. Assessing metabolic rate and indoor air quality with passive environmental sensors. J. Breath Res. 2018, 12, 036012. [CrossRef]

20. Mehta, N.M.; Smallwood, C.D.; Joosten, K.F.; Hulst, J.M.; Tasker, R.C.; Duggan, C.P. Accuracy of a simplified equation for energy expenditure based on bedside volumetric carbon dioxide elimination measurement-A two-center study. Clin. Nutr. 2015, 34, 151-155. [CrossRef]

21. Levine, J.A. Measurement of energy expenditure. Public Health Nutr. 2005, 8, 1123-1132. [CrossRef]

22. Grunwald, G.K.; Melanson, E.L.; Forster, J.E.; Seagle, H.M.; Sharp, T.A.; Hill, J.O. Comparison of Methods for Achieving 24-Hour Energy Balance in a Whole-Room Indirect Calorimeter. Obes. Res. 2003, 11, 752-759. [CrossRef]

23. Simonson, D.C.; DeFronzo, R.A. Indirect calorimetry: Methodological and interpretative problems. Am. J. Physiol. Metab. 1990, 258, E399-E412. [CrossRef]

24. Fan, J.F.; Yin, Y.H.; Xu, L.D.; Zeng, Y.; Wu, F. IoT-Based Smart Rehabilitation System. IEEE Trans. Ind. Inform. 2014, 10, 1568-1577. [CrossRef]

25. Al-Makhadmeh, Z.; Tolba, A. Utilizing IoT wearable medical device for heart disease prediction using higher order Boltzmann model: A classification approach. Measurment 2019, 147, 106815. [CrossRef]

26. Meng, K.; Chen, J.; Li, X.; Wu, Y.; Fan, W.; Zhou, Z.; He, Q.; Wang, X.; Fan, X.; Zhang, Y.; et al. Flexible Weaving Constructed Self-Powered Pressure Sensor Enabling Continuous Diagnosis of Cardiovascular Disease and Measurement of Cuffless Blood Pressure. Adv. Funct. Mater. 2018, 29, 1806388. [CrossRef]

27. Lin, Z.; Yang, J.; Li, X.; Wu, Y.; Wei, W.; Liu, J.; Chen, J.; Yang, J. Large-Scale and Washable Smart Textiles Based on Triboelectric Nanogenerator Arrays for Self-Powered Sleeping Monitoring. Adv. Funct. Mater. 2018, 28, 1704112. [CrossRef]

28. Su, Y.; Wang, J.; Wang, B.; Yang, T.; Yang, B.; Xie, G.; Zhou, Y.; Zhang, S.; Tai, H.; Cai, Z.; et al. Alveolus-Inspired Active Membrane Sensors for Self-Powered Wearable Chemical Sensing and Breath Analysis. ACS Nano 2020, 14, 6067-6075. [CrossRef]

29. Su, Y.; Xie, G.; Tai, H.; Li, S.; Yang, B.; Wang, S.; Zhang, Q.; Du, H.; Zhang, H.; Du, X.; et al. Self-powered room temperature $\mathrm{NO}_{2}$ detection driven by triboelectric nanogenerator under UV illumination. Nano Energy 2018, 47, 316-324. [CrossRef]

30. Chang, T.-B.; Sheu, J.-J.; Huang, J.-W.; Lin, Y.-S.; Chang, C.-C. Development of a CFD model for simulating vehicle cabin indoor air quality. Transp. Res. Part D Transp. Environ. 2018, 62, 433-440. [CrossRef]

31. Ji, W.; Luo, M.; Cao, B.; Zhu, Y.; Geng, Y.; Lin, B. A new method to study human metabolic rate changes and thermal comfort in physical exercise by $\mathrm{CO}_{2}$ measurement in an airtight chamber. Energy Build. 2018, 177, 402-412. [CrossRef] 
32. Matarese, L.E. Indirect Calorimetry: Technical Aspects. J. Am. Diet. Assoc. 1997, 97, S154-S160. [CrossRef]

33. Weir, J.B.D.V. New methods for calculating metabolic rate with special reference to protein metabolism. J. Physiol. 1949, 109, 1-9. [CrossRef]

34. Toubro, S.; Sørensen, T.I.; Hindsberger, C.; Christensen, N.J.; Astrup, A. Twenty-Four-Hour Respiratory Quotient: The Role of Diet and Familial Resemblance1. J. Clin. Endocrinol. Metab. 1998, 83, 2758-2764. [CrossRef]

35. Stapel, S.N.; De Grooth, H.-J.; Alimohamad, H.; Elbers, P.W.; Girbes, A.R.J.; Weijs, P.J.M.; Straaten, H.M.O.-V. Ventilator-derived carbon dioxide production to assess energy expenditure in critically ill patients: Proof of concept. Crit. Care 2015, 19, 370. [CrossRef]

36. Widmaier, E.P.; Raff, H.; Strang, K.T.; Vander, A.J. Human Physiology: The Mechanisms of Body Function, 8th ed.; McGraw-Hill Higher Education: Boston, MA, USA, 2001.

37. Li, C.; Brewer, E.; Pham, L.; Jung, H. Reducing Mobile Air Conditioner (MAC) Power Consumption Using Active Cabin-Air-Recirculation in A Plug-In Hybrid Electric Vehicle (PHEV). World Electr. Veh. J. 2018, 9, 51. [CrossRef]

38. McArdle, W.D.; Katch, F.I.; Katch, V.L. Exercise Physiology: Nutrition, Energy, and Human Performance; Lippincott Williams \& Wilkins: Philadelphia, PA, USA, 2010.

Publisher's Note: MDPI stays neutral with regard to jurisdictional claims in published maps and institutional affiliations.

(C) 2020 by the authors. Licensee MDPI, Basel, Switzerland. This article is an open access article distributed under the terms and conditions of the Creative Commons Attribution (CC BY) license (http://creativecommons.org/licenses/by/4.0/). 